\title{
O RETORNO DO RELIGIOSO NA CONTEMPORANEIDADE
}

\author{
Tiago Ribeiro Nunes
}

Resumo: $O$ presente trabalho pretende analisar os novos modos de relação, entre a civilização e o sagrado, que emergem no contexto da contemporaneidade. Partindo principalmente das formulações freudianas e lacanianas sobre o tema, nosso objetivo primordial ao longo deste artigo é estabelecer parâmetros para compreender a ocorrência do "retorno ao sagrado" no exato momento em que a humanidade enfrenta crises cada vez mais profundas e permanentes. Tal empreendimento nos permitirá verificar até que ponto o fortalecimento dos movimentos religiosos pode ser considerado como uma das conseqüências da queda dos referenciais que se realiza na contemporaneidade.

Palavras-chave: Psicanálise. Razão. Religião e ciência. contemporaneidade.

\footnotetext{
"Zaratustra, porém, ao ficar sozinho falou assim ao seu coração: 'Será possivel que este santo ancião ainda não ouviu no seu bosque que Deus já morreu?"” (F. Nietzsche).
}

O crescimento dos movimentos religiosos pelo mundo constitui um dos fenômenos mais surpreendentes da atualidade. Surpreende, sobretudo, que tal crescimento se realize exatamente em uma época marcada pelos avanços tecnológicos e pela constante referência ao discurso científico enquanto crité- 
rio de verdade. A novidade dessa ocorrência talvez esteja em um ponto bastante específico: o retorno do sagrado ao primeiro plano da dinâmica social e política se realiza no exato momento em que o saber científico, convocado com a finalidade de produzir homens melhores e sociedades mais justas, começa a expor a humanidade a crises cada vez mais profundas e permanentes, em lugar de solucionar os problemas inerentes à condição humana.

O estranhamento provocado por essa situação cria a necessidade de investigar os elementos que participam da construção/ manutenção desse cenário contemporâneo, projetado entre o sagrado e a razão, para responder a duas questões fundamentais: a) como a religião consegue resistir ao discurso científico historicamente consagrado pela tradição racionalista; b) de que modo as permanentes crises que acometem a humanidade colaboram com a proliferação desenfreada dos movimentos religiosos na atualidade. Tal empreendimento se justifica porque nos permite ampliar nossa compreensão acerca das possíveis relações existentes entre o fortalecimento de uma série de fundamentalismos, cujo impacto produzido em nossa sociedade ainda é apenas pressentido, e a generalização da crise que faz com que a nossa realidade seja experimentada, subjetiva e objetivamente, de modo cada vez mais fragmentado e descontínuo.

\section{O sono da razão produz monstros}

A fim de lançar os fundamentos do presente trabalho, partiremos de algumas considerações contidas na obra de um dos mais importantes pensadores de todo o século XX: Sigmund Freud (1856-1939). Essa escolha foi motivada, em primeiro lugar, pela grande repercussão do pensamento freudiano no campo dos saberes produzidos no ocidente desde o início do século passado. Por outro lado, essa escolha se deve ao fato de que Freud (1927/1974d), assim como outros grandes pensadores de sua época, empenhou-se decididamente em demonstrar que a religião seria, inevitavelmente, suplantada pelo saber científico. Herdeiro do espírito das luzes, ele não pôde admitir a sobrevivência dos obscurantismos religiosos em um tempo regido pelas luzes da razão. Isso justifica, em parte, sua aposta no progressivo enfraquecimento da religião e no conseqüente triunfo dos saberes científicos. Por esse motivo, dentre as referências que poderiam nortear nossa discussão sobre o tema proposto, escolhemos aquelas presentes na obra freudiana, a partir das quais tentaremos construir parâmetros que nos permitam um entendimento mais amplo acerca dos modos de relação, entre a civilização e o sagrado, que emergem no contexto da contemporaneidade. 
Iniciaremos nossa investigação por um artigo que data do outono de 1927:"O futuro de uma ilusão". Nele, Freud afirma que, em conseqüência do contínuo processo de desenvolvimento da civilização, as religiões seriam inevitavelmente suplantadas pelo saber científico (Freud, 1927/ 1974d). A convicção freudiana do desaparecimento das religiões pode ser considerada em sua relação com o que chamaremos aqui de condição moderna, pois é precisamente na modernidade que a idéia de superação contínua rumo a uma estrutura última, mais eficiente e perfeita, ganha a importância de uma meta fundamental.

Norteada pelas luzes da razão e do progresso científico, visando, acima de tudo, a superação contínua de estruturas menos completas por outras cada vez mais plenas, a modernidade pode ser considerada um período revolucionário por excelência. Priorizando a ultrapassagem dos modelos considerados falhos ou menos eficientes, o espírito moderno se caracteriza por buscar o desenvolvimento de padrões de máxima completude. Conforme nos diz Gianni Vatimo:

a modernidade pode caracterizar-se, de fato, por ser dominada pela idéia da história do pensamento como uma "iluminação" progressiva, que se desenvolve com base na apropriação e na reapropriação cada vez mais plena dos "fundamentos", que frequentemente são pensados também como as "origens", de modo que as revoluções teóricas e práticas da história ocidental se apresentam e se legitimam na maioria das vezes como "recuperações", renascimentos, retornos (Vatimo, 1996, p. VI).

Herdeiro que é do espírito das luzes, Freud aposta na superação da ilusão religiosa como etapa natural para se atingir a realidade em sua materialidade objetiva, extraindo dela (por meio de uma série de instrumentos devidamente categorizados e de validade comprovada) sua verdade última, inerente ao incansável processo de investigação e conseqüente iluminação presentes na modernidade. A expectativa freudiana de que o contínuo processo de desenvolvimento humano finalmente despertaria a humanidade para a evidência do caráter puramente ilusório das religiões, levando-a a abandonar seu vínculo ancestral com o sagrado para adotar a ciência como meio mais eficiente para lidar com a natureza e com seu Destino sempre incerto, pode ser considerada exemplar do enraizamento da teoria freudiana no modo de ser característico do pensamento moderno. Trata-se, nesse sentido, de uma conseqüência lógica: quanto mais adiantada no processo de desenvolvimento, menos a civilização necessitaria dos sortilégios religiosos. É o próprio Freud quem nos diz textualmente:"o afastamento da religião está fadado a ocorrer com a fatal inevitabilidade de um processo de crescimento, e nos encontramos exatamente nessa junção, no meio dessa fase de desenvolvimento" (Freud, 1927/1974d, p. 57). Sua opinião solidariza com a expectativa 
de que o progresso do pensamento e, por conseguinte, os avanços da ciência forneceriam uma base sólida e suficientemente forte para assegurar o declínio definitivo da religião.

Se, conforme nos afirma Freud (1927/1974d), o laço que une a humanidade ao sagrado é o desamparo, parece ser bastante legítimo supor o enfraquecimento do mesmo em face da solidificação dos saberes científicos. $\mathrm{O}$ apoio que a humanidade sempre buscou nas manifestações religiosas, motivada principalmente pela sua impotência, tende a ser finalmente superado na medida em que a ciência passa a fornecer meios cada vez mais eficientes para dominar as forças da natureza e as incertezas do Destino. Para validar sua proposta, ao mesmo tempo em que decreta neste artigo (Freud, 1927/1974d) a ultrapassagem da religião como uma etapa natural e necessária para o desenvolvimento pleno do homem e da humanidade, procura demonstrar que a "ciência não é uma ilusão" (Freud, 1927/1974d, p.71). Em contrapartida, isto é, em oposição ao caráter objetivo e não-ilusório da ciência, a religião deve passar a ser compreendida, antes de qualquer coisa, como uma ilusão. Esse é o ponto que garante e sustenta, ao nível da argumentação freudiana, o antagonismo entre ambas. É importante ressaltar que, para Freud (1927/ 1974d), uma ilusão não corresponde, necessariamente, a um erro, mas sua principal característica reside em ela ser motivada internamente por um desejo, ou seja, segundo ele, estamos diante de uma ilusão sempre que a realização de um desejo constituir um fator proeminente na motivação de alguma empresa. Isso porque, ainda segundo Freud, uma "ilusão não dá valor à verificação" (p.44), desprezando, com isso, as evidências da realidade. Os pressupostos religiosos criam ilusões que impedem que os fenômenos humanos e naturais sejam conhecidos tais como eles realmente são.

É inevitável notar o grande esforço despendido por Freud (1927/ 1974d) em seu Futuro de uma ilusão a fim de demonstrar a inconsistência do argumento segundo o qual a religião deveria ser considerada necessária à humanidade. Isso porque, convocada para responder às questões fundamentais da existência humana, a religião nunca fez mais do que envolvê-las em uma aura de mistério. Além disso, do ponto de vista da organização social, as doutrinas religiosas nunca foram capazes de fazer com que o homem abandonasse definitivamente seus impulsos destrutivos em prol da plena aceitação dos preceitos morais e éticos propostos por elas. Sendo assim, as religiões parecem ter falhado duplamente: em primeiro lugar, por nunca haverem proporcionado nenhuma ajuda efetiva na elucidação e no entendimento mais completo do homem; em segundo, por terem sido incapazes de estabelecer um modo de organização social, moral e ético como prova incontestável de seu domínio sobre impulsos instintuais e as tendências destrutivas. Freud pretende tornar evidente que, se há alguma coisa capaz de fazer homens me- 
Ihores, se existe algo eficiente para amenizar o desamparo do homem frente à natureza e ao seu Destino, esse algo, definitivamente, não é a religião, mas, certamente, a ciência.

É necessário sublinhar o fato de que a conjectura construída por Freud (1927/1974d) vai buscar no caráter experimental e demonstrável da ciência as garantias para afirmar sua legitimidade. Essas garantias é que fornecerão a sustentação para o argumento de que a ciência é mais eficiente para aparelhar o homem (em relação à natureza e ao Destino) do que o faz a religião. $O$ poder de fornecer garantias para que o homem consiga superar o seu desamparo natural é o que faz da ciência, de acordo com Freud (1927/1974d), uma ferramenta mais adequada do que a religião. Evidentemente, supõe Freud, o homem estará mais seguro para superar suas angústias e sua impotência se, abrindo mão do ineficiente misticismo religioso, decidir buscar refúgio na luminosidade que irradia do saber cientifico. De acordo com essa perspectiva, a ciência deveria aliviar o homem ao lhe permitir superar, ainda que parcialmente, seu desamparo.

Desse debate resulta, ainda, uma outra questão que gostaríamos de deixar apontada, muito embora nossos objetivos no presente artigo não nos permitam desenvolvê-la em toda a sua amplitude e profundidade. Negando qualquer dignidade à religião, e ao mesmo tempo empenhando-se em legitimar a sua substituição pela ciência, Freud dá um passo importante em direção à consumação da queda dos valores absolutos enunciada pela filosofia nietzschiana, sua predecessora. Entretanto, o passo seguinte dado por ele (Freud, 1927/1974d) pode levar o leitor, desconhecedor do conjunto de sua obra, a cometer um grave erro: supor que, para ele, trata-se apenas de substituir Deus pela ciência, mantendo intocada a dependência primordial de uma verdade total e absoluta, e devolvendo a questão ao seu estado original.

Os fundamentos dessa conclusão - correta, em parte, no que concerne ao "Futuro de uma ilusão" (Freud, 1927/1974d), mas imprecisa quanto aos apontamentos que surgem ao final da sua obra - devem-se, em parte, à prevalência, em seu pensamento, da idéia de progresso, cujo fim somente seria alcançado pela substituição de modelos menos eficientes por outros mais eficazes. Por outro lado, existe uma forte preocupação - que percorre praticamente toda a sua produção - em demonstrar como a ciência e o saber decorrente de sua prática são capazes de trazer à luz a verdade sobre os fatos naturais e humanos, o que ajuda a fortalecer o argumento anteriormente enunciado. Nesse sentido, a eleição da ciência - que não vai sem o rebaixamento da religião - ganha ares de ato redentor cujo objetivo primordial seria o resgate do homem historicamente iludido pelos obscurantismos falaciosos das práticas religiosas. 
A ênfase que Freud coloca no triunfo da ciência, decorrente da luta entre a luz da razão e as trevas do misticismo religioso, poderia, por si só, servir como demonstração de que ele, ancorado na tradição das luzes, diante da certeza irrevogável de que Deus está morto, não resistiu à atração de preencher o vazio instaurado pela queda da referência absoluta: realização necessária da superação de uma estrutura por outra ainda mais plena. $\mathrm{O}$ argumento em favor de um suposto caráter reacionário interno ao pensamento freudiano - fruto da filiação iluminista que faz existir para ele a ilusão de uma totalidade cada vez mais abrangente da razão - ganha ainda mais força se considerarmos que a simples possibilidade de realização efetiva de um vazio permanente, irreversível e, por isso mesmo, ausente de qualquer dialética, se opõe ao desejo, considerado característico em seu pensamento, de revelar, por meio da ciência natural ou psicanalítica, uma verdade última, cuja existência garantiria estabilidade e, como conseqüência disso, devolveria a ordem ao mundo. No fundo, isso quer dizer que Freud supunha a existência de um saber, ainda que velado, sobre o mundo e sobre o homem. Saber esse que deveria ser alcançado por meio do procedimento psicanalítico/ científico.

Ora, sabemos que a ciência, assim como a posição do cientista, constituiu um tabu para Freud (Lacan, 2005). Por esse motivo, é possível presumir a implicação do seu desejo na realização do ideal de elevar a psicanálise à categoria científica e, com isso, garantir seu status de verdade incorruptível. Freud também se deixou iludir pelo seu desejo ao decretar o fim da religião. Apesar disso, ao contrário da expectativa freudiana, oitenta anos depois da publicação do "Futuro de uma ilusão" (Freud, 1927/ 1974d), estão cada vez mais na pauta do dia a escalada contínua dos fundamentalismos e o recrudescimento do sentimento religioso, juntamente com a proliferação desenfreada de seitas e denominações religiosas. Ao contrário do que previu Freud, o discurso encampado pela ciência não promoveu a extinção dos laços entre a humanidade e o sagrado, mas parece ter fornecido razões ainda mais fortes para assegurar a permanência desses vínculos. Ambos os seguimentos passaram a coexistir e, por vezes, conforme veremos mais adiante, essa coexistência pressupõe certa complementaridade.

Convém destacar que nem toda a obra freudiana é solidária a essa expectativa de redenção da humanidade pela ciência, o que significa dizer que Freud não permaneceu convicto do triunfo final da razão. Podemos perceber nitidamente como o seu otimismo, herdado da tradição iluminista, contrasta com o pessimismo demonstrado por ele em textos como "Além do princípio do prazer"(1920/1974a) e"Análise terminável e interminável" (1937/1974b). Vacilando entre o otimismo arraigado na crença de uma razão plena e o pessimismo que chega ao extremo suicida de desacreditar até mesmo da validade da própria psicanálise, Freud é levado a retificar certos pontos de vista. Embora seja visível sua tentati- 
va de manter-se fiel à tradição das luzes, algumas evidências clínicas, juntamente com suas reflexões teóricas, desencadearam sua desconfiança na plenitude da razão.

O que mais se pode esperar da razão após a constatação de que toda pulsão é pulsão de morte (Freud, 1920/1974a)? Como é possível manter-se otimista e crente na plenitude do saber produzido pela razão depois de descobrir que "os horrores de que somos feitos são tanto mais perenes quanto são, para nós, irresistíveis" (Coli, 1996, p. 312)? A constatação do caráter meramente artificial e, por conseguinte, ilusório da razão faz desmoronarem os fundamentos de sustentação da filiação iluminista de Freud. As virtudes da razão esbarram na descoberta da prevalência dos impulsos destrutivos sobre os impulsos vitais, morais e civilizatórios. As ressonâncias dessa conclusão ecoam em seu "Construções em análise" (Freud, 1937/1974c), onde ele procura demonstrar que a verdade última, resultante do completo esclarecimento do inconsciente pela prática analítica, é, rigorosamente falando, impossível.

Somente depois de muita busca e esforço, Freud pôde se desprender da crença na plenitude da razão. Disso decorre o abandono da tentativa de formular um modelo definitivo capaz de explicitar exaustivamente a verdade do mundo e dos fenômenos humanos. Entendemos que é por meio dessa desistência que o niilismo se consuma em sua teoria. Ou seja, a constatação do fracasso do projeto moderno repercute decretando a ruptura entre o pensamento freudiano e a tradição herdada da era das luzes: despedida da expectativa de que algo pudesse redimir ou salvar o homem de sua condição.

Após a descoberta da prevalência da pulsão de morte, a teoria freudiana passa a situar-se definitivamente em uma encruzilhada, entre dois caminhos radicalmente distintos: a crença esperançosa na razão e a violência irreversível da realidade que "instaura o irracional como universo ilimitado" (Coli, 1996, p. 301). Conforme já afirmamos anteriormente, as relações de Freud com o iluminismo foram verdadeiramente convictas. Sabemos que a descoberta da psicanálise foi motivada pelo desejo de lançar luz sobre a verdade dos fatos inconscientes que determinam as ações humanas. Freud é portador de uma tradição que faz com que sua invenção pretenda, acima de qualquer coisa, trazer à luz a verdade do inconsciente, projetando claridade até mesmo no mais profundo da alma humana. Por esse motivo, apesar do inconsciente localizar-se, por definição, fora do campo de abrangência da razão/consciência,é impossível negar que toda a técnica desenvolvida para atuar sobre ele - o trabalho de investigação e de interpretação - celebra a plenitude da racionalidade: o inconsciente freudiano é, originalmente, um saber que deve ser cuidadosamente decifrado pelo trabalho psicanalítico.

Por outra parte, se a luz é a principal motivação da cavalgada inicial de sua teoria, para o final foram reservadas as trevas. $O$ sono da razão, 
incontestavelmente, produz seus monstros. Isso porque, por maior que seja a luminosidade da razão, sua luz"nunca é triunfante, mas possui um caráter agônico, uma existência dificultosamente obtida diante do escuro" (Coli, 1996, p. 310). Nas últimas formulações freudianas não há mais qualquer claridade, nem luz de espécie alguma:

Porque a razão dorme, e a sua luz se apaga. Isso pressupõe, portanto, um esforço áspero de vigília, enquanto a noite, o obscuro, o monstruoso, existem por direito natural, prévios a qualquer racionalidade. Ao invés do triunfo do pensamento verdadeiro da razão, da claridade que invade para sempre o universo, o que se descobre é uma predominância invencível das trevas. (Coli, 1996, p. 310)

A razão e a verdade revelaram-se demasiado precárias e transitórias. A real condição humana, submetida ao tempo destruidor, à doença e às atrocidades levadas a cabo pelas duas grandes guerras do século XX, se sobrepõe violentamente ao ideal artificial da racionalidade. Além disso, a ciência (cujas propostas iniciais incluíam a ampliação contínua do domínio humano sobre a natureza e a compreensão dos fenômenos naturais/sociais) tem introduzido "um monte de coisas perturbadoras na vida de todos" (Lacan, 2005, p. 65). Perturbação e mal-estar: afirmação cada vez mais conclusiva da fragilidade da existência.

\section{O mal-estar na contemporaneidade}

Na contemporaneidade, a razão dá mostras inquestionáveis de seu cansaço. À beira de um colapso definitivo, o panorama construído na atualidade nos informa que o ideal da racionalidade cedeu lugar para o caos: subversão total da dimensão da ordem e da lei. O tempo presente é um tempo permanentemente atormentado pela crise. Nosso século, dominado pela velocidade vertiginosa das transformações técnicas e tecnológicas, nos confirma que o desamparo do homem não desapareceu, mas se revelou ainda mais irremediável do que sequer ousamos imaginar algum dia. $\mathrm{O}$ avanço do campo de abrangência das técnicas científicas parece ser diretamente proporcional à emergência do sentimento cada vez mais intenso de angústia por demonstrar seguidamente que há sempre algo, imprevisível, que insiste em escapar ao esforço racional de explicação e de previsão.

Além da presença freqüente do imponderável, existem as incontroláveis ameaças biológicas, a nunca completamente superada ameaça de destruição nuclear, o temor frente às incalculáveis conseqüências das intervenções humanas na natureza, a barbárie das duas grandes guerras e das guerrilhas que dominam nos grandes centros urbanos que demonstram, de modo contundente, quão tênue é o fio que susten- 
ta a humanidade. Valéry declara com perplexidade o mútuo pertencimento entre o horror e as virtudes da razão (operacionalizadas pelos saberes científicos): "Sem dúvida, foi preciso muita ciência para matar tantos homens, dissipar tantos bens, aniquilar tantas cidades em tão pouco tempo" (Valéry citado por Novaes, 1996, p. 9). Diante do quadro pintado na contemporaneidade, o sentimento de angústia se torna absolutamente inevitável. Em lugar de amenizar seu estado de permanente incerteza, fornecendo ao homem um caminho seguro para trilhar, a ciência denuncia de modo fulminante a impotência da civilização frente ao imprevisível que teima em envolvê-la e se multiplicar à sua volta.

Na medida em que a ciência - convocada não apenas por Freud, mas por toda uma geração de pensadores descendentes da tradição iluminista a fim de amenizar, ainda que parcialmente, as angústias que tanto atormentavam a humanidade - expõe o caráter limítrofe de uma realidade incontrolável, é possível ver no recrudescimento do sentimento religioso e no fervoroso apelo à religião do qual somos testemunhas uma tentativa desesperada de estabilizar e organizar a loucura que domina o dia-a-dia da atualidade. Nesse sentido, o retorno ao sagrado se realiza enquanto esforço de devolver à humanidade uma ordem, ainda que artificial. É Lacan quem nos diz que:

O numenoso surge a cada passo e, inversamente, cada passo do numenoso deixa um rastro, engendra um memorial. Não é preciso muito para que um templo se erga, para que um novo culto se instaure. O numenoso pulula e age por toda parte na existência humana, tão abundante aliás, que algo de dominação deve finalmente manifestar-se, por meio do homem, que não se deixe transbordar. (Lacan, 1997, p. 211)

Hoje, a freqüente emergência de movimentos religiosos, assim como o empenho aplicado ao fortalecimento das instituições que sobrevivem da veiculação do sagrado, nos demonstram até que ponto o território dos fundamentalismos tem se difundido.É possível, inclusive, que os vínculos que unem a civilização ao sagrado sejam mais fortes em nossa época do que o foram em outros momentos históricos. A zona limítrofe à qual a história da civilização nos trouxe causa tanta perplexidade que a retomada do culto ao Eterno não faz outra coisa senão ilustrar a tentativa de suportar o choque de uma realidade irremediavelmente fragmentada. A difusão do sagrado testemunha a súplica desesperada para que os estiIhaços dessa realidade sejam reunidos, ainda que de modo bastante precário, a fim de restabelecer sua unidade imaginária.

Por essa razão, Lacan (2005) dirá que a religião está destinada a triunfar em nossa época. $O$ triunfo da religião sobre a ciência e também sobre a psicanálise se justifica porque, na prática religiosa, Deus é a garantia de que há, ainda, uma verdade estável e permanente. O Onipoten- 
te confere estabilidade para aquilo que é, em si mesmo, pura contingência. Realizando um movimento contrário, a ciência e, mais precisamente, a psicanálise, nos informa que o estado real de nossa realidade é exatamente aquilo que podemos assistir a olho nu, e que as mídias, ao seu modo sensacional, não cessam de nos informar: jogo contínuo com o imprevisível, ausência de garantias ou controle.

Nesse sentido, a presença vigorosa da religião na contemporaneidade pode ser vista enquanto um esforço a mais na tentativa de fazer existir uma unidade estruturada: construção de um território seguro, que passa, necessariamente, pela negação da realidade em seu estado de pura dispersão. Por esse motivo, a religião fervilha e se prolifera de modo desenfreado, costurando as peças soltas que compõem a nossa realidade e procurando desmentir o caráter fragmentário de uma sociedade cada vez mais acossada pelo real de sua condição. Ao contrário do que supunha Freud (1927/1974d), o futuro da ilusão religiosa não é o desaparecimento, mas o triunfo: a religião triunfará inclusive sobre a psicanálise, que, por sua vez, terá que sobreviver a ela (Lacan, 2005). Segundo afirma Lacan, a religião:

Não triunfará apenas sobre a psicanálise, triunfará sobre muitas outras coisas também. É inclusive impossível imaginar quão poderosa é a religião... O real, por pouco que a ciência aí se meta, vai se estender, e a religião terá então muito mais razões ainda para apaziguar os corações. A ciência é novidade, e introduzirá um monte de coisas perturbadoras na vida de todos. Ora, a religião, sobretudo a verdadeira, tem recursos de que sequer se suspeita. Por hora, basta ver como ela fervilha. É absolutamente fabuloso. (Lacan, 2005, p. 65)

O espírito das luzes silenciou o universo aterrorizando Pascal e, por extensão, todo o restante da humanidade. Desde então, tem-se feito todo o possível para amenizar o mal-estar que acomete a civilização e que resulta da generalização desagregadora do silêncio na atualidade. Esse movimento de reação é a chama que faz fervilhar em nossos dias o culto ao sagrado. É na garantia de estabilidade fornecida pelo Divino que a humanidade angustiada busca se refugiar. Tal estabilidade, entretanto, não passa de uma ilusão que procura negar o caráter imprevisto da contingência superpondo a isso a imagem de uma realidade estável e organizada pelo direito e pela lei. Em uma época sem identidade, o engajamento nos movimentos religiosos produz, pela negação do caráter irremediavelmente fragmentado da cena contemporânea, uma identidade reacionária e disposta a todo tipo de combate para garantir a ilusão de homogeneidade entre os seus fiéis.

Se o silêncio que aterrorizava Pascal permanece propagando seus efeitos na sociedade contemporânea, parece haver evidências suficientes para afirmar que ele passou a ser experimentado de uma forma com- 
pletamente nova: o pânico. A novidade dessa experiência que se torna plenamente difundida na sociedade pós-industrial e globalizada amplia no homem a dimensão daquilo que não pode ser controlado. A angústia, em relação à qual sempre foi possível se refugiar pela construção de territórios seguros, torna-se implacável desde o momento em que esses territórios cuidadosamente construídos passam a ser ineficientes para salvaguardar em relação à ameaça que ronda. O que desencadeia o terror é precisamente o fato de que as ameaças provêm de todas as partes, inclusive de dentro do próprio organismo.

Quando as tentativas de circunscrever um campo de onde se poderia facilmente distinguir entre o bom e o mau, entre o certo e o errado etc., fracassam, e, além disso, quando a desmesura da pulsão irrompe no primeiro plano da cena, o resultado é a vertigem. Como nos afirma Suely Rolnik, o homem está completamente tomado de pânico:

\begin{abstract}
por encontrar-se exposto ao trágico numa proporção provavelmente mais violenta e recorrente do que no final do século passado, o que provoca uma desestabilização ainda maior. Como o trágico continua sendo um trauma, a intensificação da disparidade que o caracteriza passa a ser vivenciada como incidindo sobre a própria vida: este homem sente seu organismo habitado por um perigo progressivo de perda de organicidade, de desorientação, que a qualquer momento pode chegar a um verdadeiro enlouquecimento do corpo e levá-lo à morte. Sente-se inteiramente impotente para fazer algo que breque este processo, pois ele acontece imperceptivelmente no segredo de suas entranhas.É como se a vida escapasse de suas mãos (Rolnik, 2005, p. 6).
\end{abstract}

Acometido pelo pânico, o homem contemporâneo entende que é preciso construir estratégias que lhe proporcionem algum alívio do seu mal-estar. Por esse motivo, a defesa contra o processo de dissolução que ameaça o sentimento de organicidade de modo cada vez mais irreversível - passa a constituir um dos programas mais fundamentais e caros à contemporaneidade. Isso faz da nossa época um terreno bastante propício para o fortalecimento das atitudes reacionárias que negam a realidade em sua condição fragmentada em busca do suposto alívio proporcionado pela ilusão da estrutura. Para remediar o mal-estar e o sofrimento provocado por uma realidade em processo ininterrupto de desdobramento, o homem se vê persuadido a aderir àqueles discursos cujo principal intuito parece ser restaurar ao mundo sua estabilidade pelo exorcismo da dispersão e pela anulação do contingente. Desse modo, o afluxo da humanidade ao território do sagrado parece estar ligado à tentativa de defender-se contra a insuportável perda da organicidade que se realiza na contemporaneidade.

Supor a existência de uma ordem, instaurada e regida pelo Onipotente e Onisciente Criador, permite a construção de uma ilusão que pare- 
ce ser absolutamente indispensável ao nosso tempo. Por esse motivo, é bastante provável que a proliferação do culto ao divino juntamente com o avanço desenfreado dos fundamentalismos religiosos constitua mais uma das manifestações sintomáticas características da nossa época. Até onde podemos ver, aquilo que norteia esse retorno ao sagrado em nosso tempo é a solidez e a permanência inabalável das verdades produzidas sob a forma da revelação. A verdade, estável e absoluta, produzida pela revelação religiosa, cria o engano de que ainda há, no interior dessa dissolução generalizada, ao menos um discurso - o religioso - capaz de manter-se de pé. Somente um discurso assim articulado pode ser capaz de refugiar a humanidade desolada fornecendo a ela a salvaguarda de uma Providência que regula com bondade e justiça toda a ordem universal. Nesse ponto reside, talvez, o principal trunfo das práticas religiosas em relação aos outros saberes: a condição de produzir uma consistência imaginária que devolve à realidade fragmentada a ilusão de conjunto. A unidade imaginária, entretanto, apesar de sua fantástica capacidade de cerzir a realidade despedaçada, não passa de uma reação cuja função primordial é dissimular a inconsistência do Outro.Tal procedimento, portanto, não produz mais do que um suporte canhestro cujo objetivo fundamental é fazer com que a humanidade consiga suportar, pela ilusão de conjunto do Todo, o choque da cena contemporânea.

\section{Contemporaneous religious return}

Abstract: The present work intends to discuss the new relations between the civilization and the sacred that appears in the contemporary context. Beginning by the Freudian and Lacanian formulations about this theme, our goal is to establish some references in order to understand the "return to the sacred" at the moment where the humanity faces deeper and more permanent crises each time. Such challenge will allow us to verify how the increase in the religious movements can be considered as a reaction against the fall of the references that happens nowadays.

Keywords: Psychoanalysis. Reason. Religion and science. Nowadays.

\section{Le retour du sacré dans la contemporanéité}

Résumé: Ce travail a pour but d'analyser les nouveaux modes de relation, entre la civilisation et le sacré, qui émergent dans le contexte de la contemporanéité. En partant, surtout, des formulations freudiennes et lacaniennes sur ce thème, notre principal objectif, dans cet article, est d'établir des paramètres 
pour comprendre l'occurence du « retour au sacré » dans le moment exacte où I'humanité fait face à des crises de plus en plus profondes et permanentes. Tel entreprise nous permettra de vérifier jusqu'où l'affermissement des mouvements religieux peut être consideré comme l'une des conséquences de la chute des référenciels qui se réalise dans la contemporanéité.

Mots-clés: Psycanalyse. Raison. Réligion et science. Contemporanéité.

\section{El retorno del sagrado en la contemporaneidad}

Resumen: El presente trabajo trata de analizar los nuevos modos de relación entre la civilización y el sagrado, que surge en el contexto de la contemporaneidad. Partiendo principalmente de las formulaciones freudianas y lacanianas sobre el asunto, nuestro objetivo primordial al largo de este trabajo es establecer parámetros para comprender la ocurrencia del retorno al sagrado en el momento en que la humanidad enfrenta crisis cada vez más profundas y permanentes. Tal empresa nos permitirá verificar hasta que punto el fortalecimiento de los movimientos religiosos puede ser considerado una de las consecuencias de la decadencia de los referenciales en la contemporaneidad.

Palabras-clave: Psicoanalisis. Razon.Religion y ciência. Comtemporaneidad.

\section{Referências}

Coli, J. (1996). O sono da razão produz monstros. In A. Novaes (Org.), A crise da razão (pp. 301-312). São Paulo: Companhia das Letras.

Freud, S. (1974a). Além do princípio do prazer. In S. Freud, Edição standard brasileira das obras psicológicas completas de Sigmund Freud (J. O. A. Abreu, trad., Vol. 18, pp. 17-85). Rio de Janeiro: Imago. (Trabalho original publicado em 1920)

Freud, S. (1974b). Análise terminável e interminável. In S. Freud, Edição standard brasileira das obras psicológicas completas de Sigmund Freud (J. O. A. Abreu, trad., Vol. 23, pp. 247-287). Rio de Janeiro: Imago. (Trabalho original publicado em 1937)

Freud, S. (1974c). Construções em análise. In S. Freud, Edição standard brasileira das obras psicológicas completas de Sigmund Freud (J.O.A.Abreu, trad., Vol. 23, pp. 291-304). Rio de Janeiro: Imago. (Trabalho original publicado em 1937) 
Freud, S. (1974d). O futuro de uma ilusão. In S. Freud, Edição standard brasileira das obras psicológicas completas de Sigmund Freud (J. O. A. Abreu, trad., Vol. 21, pp. 15-71). Rio de Janeiro: Imago. (Trabalho original publicado em 1927)

Freud, S. (1974e). Totem e tabu. In S. Freud, Edição standard brasileira das obras psicológicas completas de Sigmund Freud (O.C.Muniz, trad.,Vol. 13, pp. 20191). Rio de Janeiro: Imago. (Trabalho original publicado em 1913)

Lacan, J.(1997). O seminário. Livro 7: a ética da psicanálise (A. Quinet, trad.). Rio de Janeiro: Jorge Zahar.

Lacan, J. (2005). O triunfo da religião, precedido de, Discurso aos católicos (A.Telles, trad). Rio de Janeiro: Jorge Zahar.

Novaes, A. (1996). A lógica atormentada. In A. Novaes (Org.), A crise da razão (pp. 9-18). São Paulo: Companhia das Letras.

Rolnik, S. (1995). O mal-estar na diferença. Recuperado em 05 de abril de 2007, de http://www.pucsp.br/nucleodesubjetividade/Textos/SUELY/ Malestardiferenca.pdf.

Vatimo, G. (1996). O fim da modernidade: niilismo e hermenêutica na cultura pós-moderna (E. Brandão, trad). São Paulo: Martins Fontes.

Tiago Ribeiro Nunes, Psicanalista, Professor do Departamento de Psicologia da Universidade Federal de Goiás (UFG/CAC). Rua Quinze de Novembro, n 32, CEP: 74553015, Setor Centro Oeste, Goiânia/GO. Endereço eletrônico: ribeiro.nunes@gmail.com

Recebido em: $17 / 08 / 2007$

Aceito em: 12/07/2008 